\title{
Investigation of urban microclimate parameters in an urban center
}

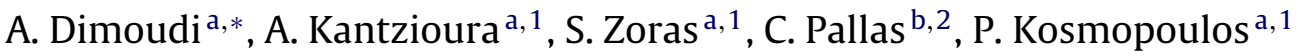 \\ a Laboratory of Environmental and Energy Efficient Design of Buildings and Settlements, Department of Environmental Engineering, Democritus University \\ of Thrace, Greece \\ ${ }^{\mathrm{b}}$ Department of Technical Services, Serres Municipality, Greece
}

\section{A R T I C L E I N F O}

\section{Article history:}

Received 21 September 2012

Received in revised form 2 April 2013

Accepted 25 April 2013

\section{Keywords:}

Urban microclimate

Urban canyon

Microclimate parameters

Cooling degree hours

\begin{abstract}
A B S T R A C T
The local climate of an urban area can be greatly affected by the urban thermo-physical and geometrical characteristics, anthropogenic activities and heat sources present in the area. A growing interest in microclimate issues has been raised as they represent important factors in achieving energy conservation and sustainability inside the cities, where a big amount of the population lives.

This paper presents the analysis of microclimatic conditions in urban street canyons in a city of Northern Greece, Serres. A number of field measurements were carried out during summer 2011 aiming at investigation of the microclimate parameters that affect thermal conditions in the city's streets. The present study focused on the experimental investigation of wind characteristics (speed and direction) and thermal profile (air temperature distribution) of an area consisted by several building blocks in the city center.

The data analysis concentrated at the differences that were observed inside the canyons, along different streets and the comparison between the microclimatic parameters in the urban center and the suburban area. Estimation of the cooling degree days for the area shows the increased energy needs of the surrounding buildings during the summer period.
\end{abstract}

(c) 2013 Elsevier B.V. All rights reserved.

\section{Introduction}

The local climate of an urban area can be greatly affected by the urban thermo-physical and geometrical characteristics, anthropogenic activities and heat sources present in the area. The urban environment modifies micro-climate in numerous ways [1]. So, there is a growing interest in microclimate issues as they represent important factors in achieving sustainability inside the cities, where a big amount of the population lives.

The urban growth has caused significant changes in the radiant balance of the urban space, the convective heat exchange between the ground and the buildings, the air flowing above the urban area and the heat generation within the city. The main consequence of these effects is the difference of air temperature between urban and rural areas [2]. This called urban heat island (UHI) phenomenon, it is responsible for $1-6^{\circ} \mathrm{C}$ higher air temperatures in the city center than the surrounding suburban and rural areas and is the most obvious climatic manifestation of urbanization [1].

\footnotetext{
* Corresponding author. Tel.: +30 2541079 388; fax: +30 2541079388 .

E-mail addresses: adimoudi@env.duth.gr (A. Dimoudi), pallas@serres.gr (C. Pallas).

1 Tel.: +3025410 79 388; fax: +302541079388.

2 Tel.: +302321350141.
}

The phenomenon is present in many cities around the world [2-5]. The urban microclimate is mainly influenced by increased building density with the canyon geometry, the use of materials with inappropriate optical and thermal properties, the lack of green spaces, increased anthropogenic heat and increased air pollution $[6,7]$. So, the main differences between the urban and rural microclimatic conditions that affect human comfort result from differences in air temperatures and wind speeds [8].

UHI elevated temperatures, particularly in summer, can affect the city's environment and quality of life. They can cause health problems and heat islands can lead to worsened air quality because of accelerating rate production of photochemical ozone in high temperature and increasing emission of ozone precursors [9]. UHI's are also an energy efficiency concern, because increased urban temperatures also increase energy consumption, especially during the summer period, peak energy demands and energy prices, whilst also increasing considerably the ecological footprint of cities [2,10-12].

In order to limit the effect of heat islands and improve microclimate conditions various mitigation techniques have been proposed involving the use of highly reflective materials, use of cool sinks and increased plantation $[1,13]$. Trees and green areas have a large effect at moderating the microclimate and also contribute at cooling the cities $[14,15]$ as evapotranspiration from vegetation foliage reduces air temperature and increases humidity [16]. Vegetated areas are known to be comparatively cooler during daytime than most other 


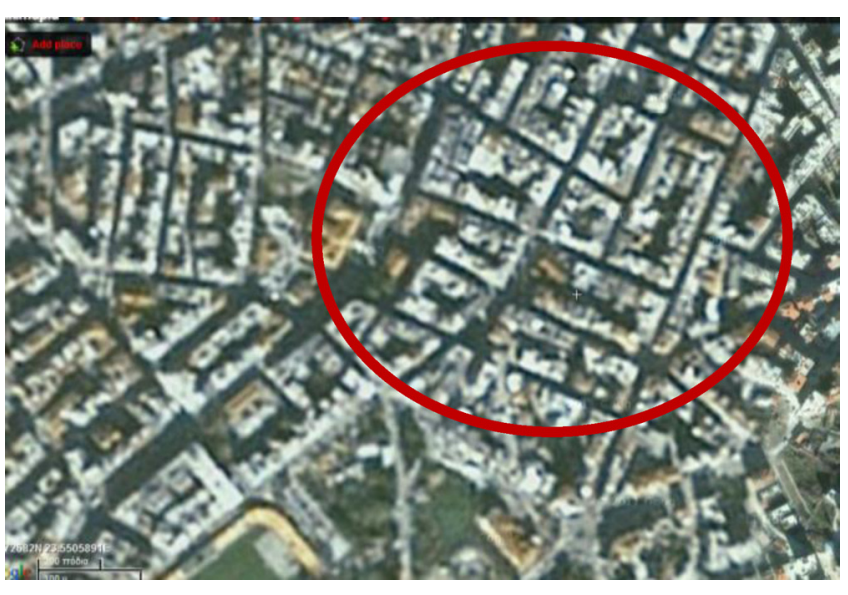

Fig. 1. View of the selected study area.

urban elements [17]. Mitigating the heat islands effect is therefore a key element to achieving sustainability in a city and it can be done by improving the urban microclimate [2].

The urban microclimate and measurement of the city's heat island can be investigated by different approaches, like by fixed monitoring stations, by mobile measurements, inside and outside the urban areas, by remote sensing. In order to research the parameters that influence the urban microclimate, measurements at ground level and/or different heights around buildings and city's blocks, scale models and simulation work can be employed [18].

The aim of the current study was the investigation of microclimatic conditions in a densely constructed urban complex consisting of different building blocks in the center of a medium size city and document the UHI. The investigation took place in a city at the Northern Greece, which is considered as one of the warmest cities during the summer period in Northern Greece. The parameters that were examined was air temperature, wind characteristics, as these characteristics are affected by the canyon geometry, orientation, weather conditions and thermal properties of the constructive materials.

\section{Methodology}

\subsection{Site description}

The investigation was conducted at the Serres city, located at $41^{\circ} 05^{\prime} \mathrm{N}$ and $23^{\circ} 33^{\prime} \mathrm{E}$, in Northern Greece in an altitude of about $61 \mathrm{~m}$ above the sea level. The study area is located in the central part of the city which is characterized by a densely urban structure (Fig. 1). The site considered has about 14 building blocks and 10 streets. The buildings are characterized by $4-5$ floors height and are built in the decade of 1970s (Fig. 2). The ground floor of the buildings in the blocks is for commercial use (shops), while the rest of the floors are residences. Each floor is about $3 \mathrm{~m}$ and the ground floor is $5 \mathrm{~m}$ high. The ratio Height of the buildings to Width of the road in the urban canyon is $\mathrm{H} / \mathrm{W}=1.4$ in average. The majority of walls' façade is beige in color and about $35 \%$ of them are covered by windows.

The selected site corresponds to a typical geometric configuration of the urban streets in the center of the city (Fig. 2). The buildings bound roads of $8 \mathrm{~m}$ width, with about $2 \mathrm{~m}$ width sidewalks on both sides $-1.5 \mathrm{~m}$ in one street. The streets are covered by asphalt with pavements on both sides, covered mainly by light color, conventional pavement (concrete) tiles. Car parking is allowed on both sides of the streets.

In the densely built study region there are only three restricted open spaces (a small green area in a crossway road, a park and a

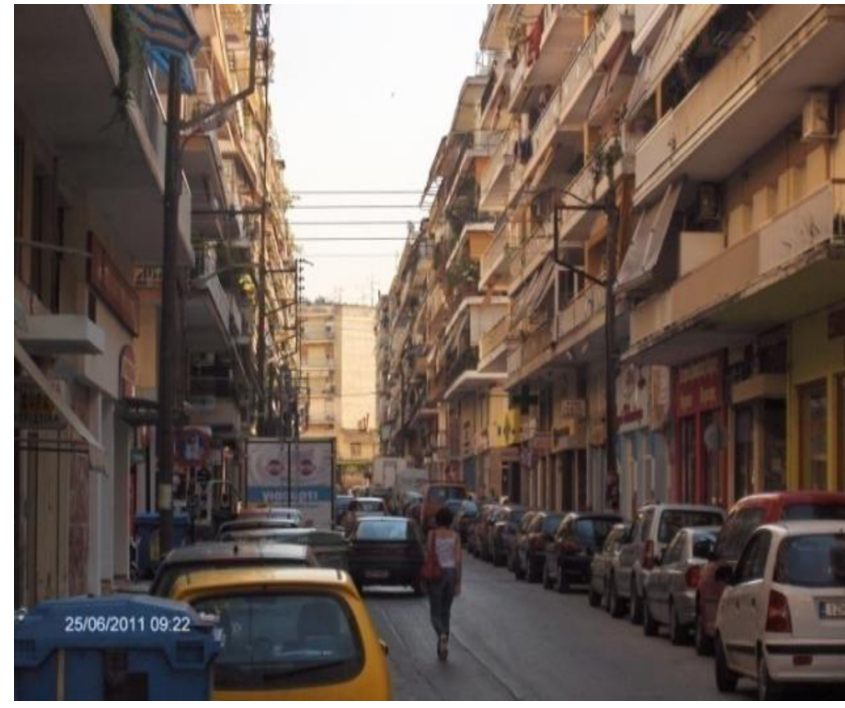

Fig. 2. Urban geometry and streets' configuration of the study area.

playground area), which are covered by green, soil and tiles. These areas could be to reclaim so as to configure better microclimatic conditions inside the urban canyons. There is also a church and a small school building with a lower height than the other blocks, and a yard around.

Analysis of the climatic data for a period of 30 years (1973-2004) from the cities in Northern Greece documents that the city of Serres is characterized by the highest air temperatures in summer period in Northern Greece. The city presents intense heat problem during summer with thermal episodes of high air temperature that exceed the $40{ }^{\circ} \mathrm{C}$ (Table 1 ).

\subsection{Description of monitoring campaign}

A number of experimental procedures were organized in the study area. The field surveys involved detailed microclimatic monitoring by two different monitoring campaigns, one with a fixed measurements net and one with a set of portable equipment.

The first campaign included continuous measurement of microclimatic parameters and specifically the air temperature $(\mathrm{T})$, the relative humidity $(\mathrm{RH})$, the wind speed (WS) and the wind direction (WD). The mini weather stations for monitoring the air temperature

Table 1

Meteorological data for Serres, 1971-2004.

\begin{tabular}{lccc}
\hline & June & July & August \\
\hline Absolute (maximum) & air temperature $\left({ }^{\circ} \mathrm{C}\right)$ & & \\
Average & 36.0 & 37.7 & 36.7 \\
Maximum & 39.4 & 43.8 & 42.0 \\
Minimum & 32.5 & 34.6 & 31.7 \\
Average maximum air temperature $\left({ }^{\circ} \mathrm{C}\right)$ & & \\
Average & 30.2 & 32.4 & 31.8 \\
Maximum & 32.2 & 35.6 & 35.5 \\
Minimum & 26.7 & 30.0 & 27.8 \\
Average air temperature $\left({ }^{\circ} \mathrm{C}\right)$ & & \\
Average & 24.5 & 26.6 & 25.7 \\
Maximum & 26.4 & 29.4 & 28.7 \\
Minimum & 21.8 & 24.6 & 22.1 \\
Relative humidity $(\%)$ & & & \\
Average & 54.7 & 52.0 & 55.0 \\
Maximum & 64.4 & 62.0 & 65.0 \\
Minimum & 42.6 & 39.1 & 41.8 \\
Wind speed $(\mathrm{m} / \mathrm{s})$ & & & \\
Average & 2.1 & 1.9 & 1.6 \\
Maximum & 5.0 & 4.7 & 4.0 \\
Minimum & 0.4 & 0.3 & 0.4 \\
\hline
\end{tabular}




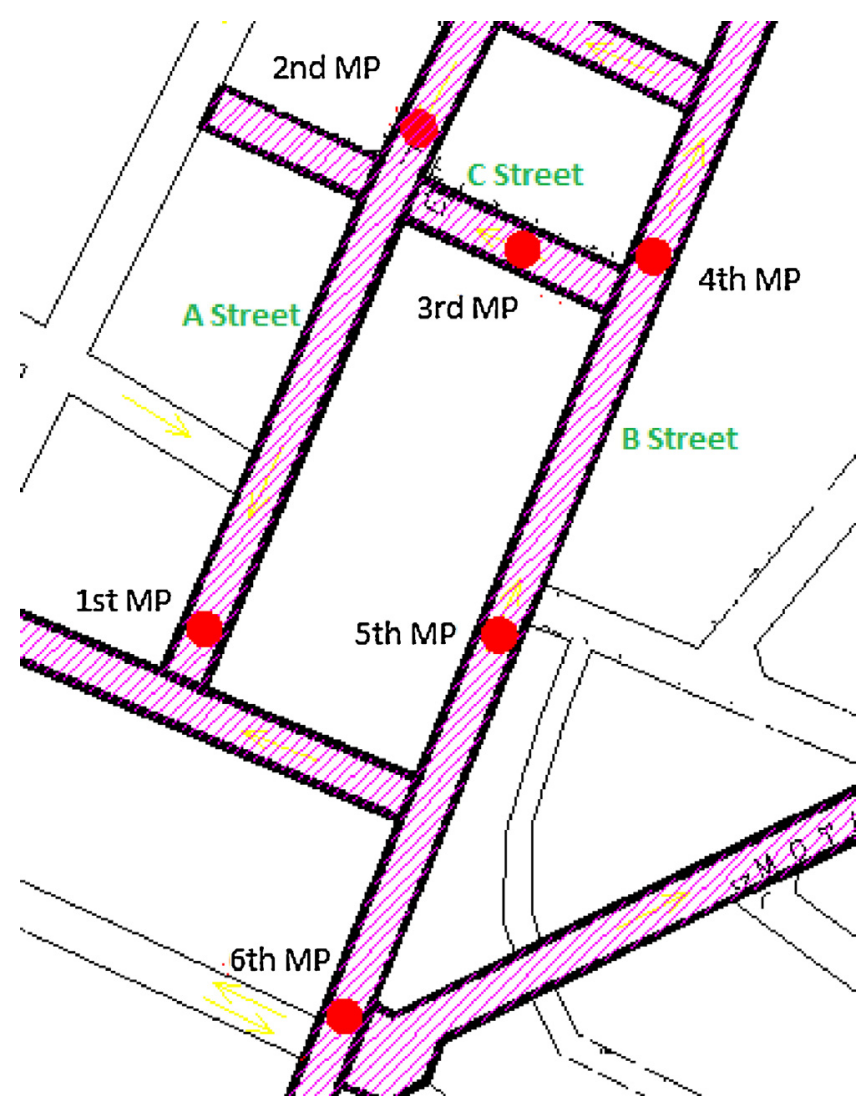

Fig. 3. View of the selected stations of fixed measurements.

and relative humidity were placed in 6 fixed measurements points (MP) in the study area (Fig. 3). The location of the monitoring equipment took into account the geometric and the morphological characteristics of the region. Two of the weather stations were placed along the same road (A Street, 1MP, 2MP), one in the vertical direction road (C Street, 3MP) and the other three along the parallel road to the first (B Street, 4MP, 5MP, 6MP). In this aforementioned road (B Street), one station was at the beginning of the street canyon, one at the middle and one at the end near to a crossway of five roads and a small green roundabout (Fig. 3).

The fixed weather stations for air temperature and humidity were placed at about $4.5 \mathrm{~m}$ height and recorded the microclimatic data every $5 \mathrm{~min}$.

The sensor for recording wind speed and direction was an ultrasonic wind sensor of 2-axis, with low start speed in $0.01 \mathrm{~m} / \mathrm{s}$. This

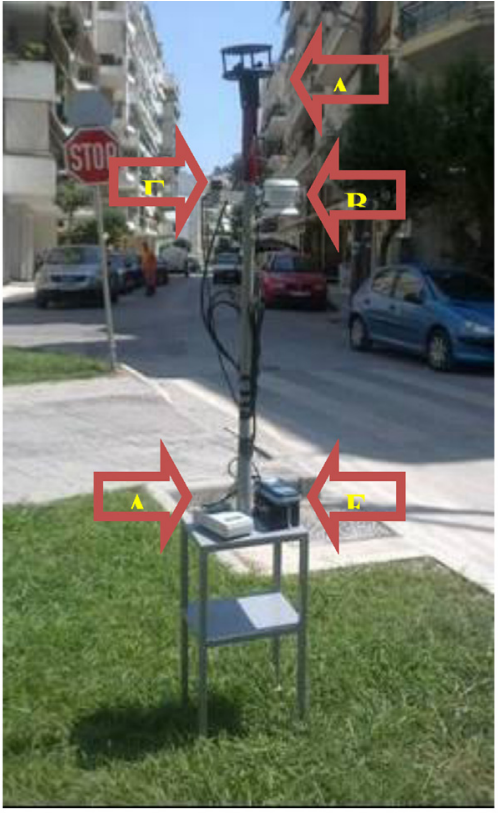

A. Wind speed \& direction sensor, B. Air temperature sensor,

Г. Global solar irradiance sensor, $\Delta$. Data logger, E. Battery

Fig. 4. The portable weather station.

sensor is suitable for measuring wind speed in densely urban centers, where the wind speed can be extremely low due to urban configuration and geometry. During the measuring period, the sensor was firstly placed for 6 days at the fourth measurement point (4th MP, B Street) and for the rest period at the first point (1st MP, A Street). It recorded data every $10 \mathrm{~min}$.

In order to evaluate the microclimatic conditions within the urban street, a series of measurements were collected by a portable weather station (Fig. 4). Table 2 describes the technical characteristics of all measurement instruments. The portable station recorded at $1.8 \mathrm{~m}$ height the air temperature, the relative humidity, the wind speed and wind direction and solar radiation. This height was selected as representative of the conditions prevailing at pedestrian's level and additionally measurements are not affected by activities at pedestrian level (walking, cars' movement).

The experimental procedures with the portable weather station were carried out during the midday hours from 13:00 to 16:00 at hot summer days. The measurements took place at the six measurements points, in both sides of the road, as the microclimatic parameters, such as shadowing, are influenced by the street's orientation and the urban geometry.

Table 2

Technical characteristics of measurement instruments.

Temperature/relative humidity

Wind speed/wind direction
HOBO Pro V2 Temp/RH data logger

Temperature range/accuracy

RH measurement range/accuracy

Outdoor temperature sensor

Temperature range/accuracay

Data logger

WindSonic ultrasonic wind sensor

Wind direction range

Operating temperature

Wind speed range/accuracy

Resolution/response time

Threshold

Delta OHM 2102.2 photo-radiometer

Operating temperature

Storage temperature
$-40{ }^{\circ} \mathrm{C}$ to $70^{\circ} \mathrm{C} / \pm 0.2^{\circ} \mathrm{C}$ over $0^{\circ}$ to $50^{\circ} \mathrm{C}$ $0-100 \% \mathrm{RH} / \pm 2.5 \%$ from $10 \%$ to $90 \%$

From $-50^{\circ} \mathrm{C}$ to $+90^{\circ} \mathrm{C} / \pm 0.15^{\circ} \mathrm{C}$ Stylitis 10

2-Axis ultrasonic wind senso

$0-359^{\circ}$

$-35^{\circ} \mathrm{C}$ to $+70^{\circ} \mathrm{C}$

$0-60 \mathrm{~m} / \mathrm{s}$ (116 knots)/ $\pm 2 \%$ @12 m/s

$0.01 \mathrm{~m} / \mathrm{s}(0.02$ knots $) / 0.25 \mathrm{~s}$

$0.01 \mathrm{~m} / \mathrm{s}$

$-5^{\circ} \mathrm{C}$ to $+50^{\circ} \mathrm{C}$

$-25^{\circ} \mathrm{C}$ to $+65^{\circ} \mathrm{C}$ 
Table 3

Summary of microclimatic variables for the surveys.

\begin{tabular}{ll}
\hline Microclimatic variables & \\
\hline Wind speed & WS \\
Air temperature & $T_{\text {air }}$ \\
DT measurement point & MP \\
Wind direction & WD \\
Temperature difference & DT \\
Greater Serres area & GSA \\
\hline
\end{tabular}

Also, data from the nearest suburban meteorological station of the Hellenic National Meteorological Service were used to compare the climatic condition of Greater Serres Area (GSA) and microclimatic condition of the study area. The meteorological station is located in South-East suburban area of the city, in a not densely populated area.

The experiments that are presented in this paper were performed in the period of 27 July to 24 August 2011. High temperatures were prevailed during this summer period.

\section{Results and discussion}

A discussion is initially presented focusing on the microclimatic parameters of wind characteristics and air temperature, inside the urban canyons in the city's center. The microclimatic data recorded in the study area are also presented along with the meteorological data of the GSA for investigating the correlation and the interaction between them (Table 3 ).

The discussion focuses on analysis of thermal behavior inside the streets, the comparison between the microclimatic parameters of the urban center and suburban area.

\subsection{Analysis of the air flow}

The main direction of the air flow in the A Street is East (E) and South (S) with incidence amount of $28.5 \%$ and $27.9 \%$ of the monitored period, respectively. The more intensive wind has South-West direction (SW) with average wind speed of $0.7 \mathrm{~m} / \mathrm{s}$. It follows the South (S) direction winds with average wind speed $0.58 \mathrm{~m} / \mathrm{s}$, which are also the second appeared main direction winds
Table 4

Wind flow characteristics in two streets, in study area.

\begin{tabular}{|c|c|c|c|c|c|}
\hline & \multirow[t]{2}{*}{ Main WD } & \multicolumn{2}{|c|}{ More intensive wind } & \multicolumn{2}{|l|}{ Max } \\
\hline & & WD & WS (m/s) & WD & WS $(\mathrm{m} / \mathrm{s})$ \\
\hline A Street & $\mathrm{E}(28.5 \%)$ & SW & 0.7 & SW & 1.5 \\
\hline B Street & SW (35.6\%) & $\mathrm{NE}$ & 0.5 & NE & 1.5 \\
\hline
\end{tabular}

in the street (Fig. 5). The maximum wind speed that recorded during the experimental period was $1.5 \mathrm{~m} / \mathrm{s}$ for $\mathrm{SW}$ direction.

In the B Street, the main direction of the air flow is South-West (SW), for the $35.6 \%$ of the monitored period. The more intensive winds have North-East (NE) direction with average wind speed $0.5 \mathrm{~m} / \mathrm{s}$ and the South-West (SW) and West (W) with average wind speed $0.45 \mathrm{~m} / \mathrm{s}$ (Fig. 5). The maximum wind speed was $1.5 \mathrm{~m} / \mathrm{s}$, North-East direction (Table 4).

In the A Street, the wind speed was increasing from the 9:00 to $12: 00 \mathrm{~h}$, during the measurement period. At 12:00 the average wind speed was about $0.6 \mathrm{~m} / \mathrm{s}$. For the next $5 \mathrm{~h}$ the wind speed had high values and the highest average wind speed was $0.7 \mathrm{~m} / \mathrm{s}$ at 15:00. During the afternoon time, the wind speed was decreasing (Fig. 6).

In the B Street, the wind speed was increasing until 14:00 h, where it was observed the higher wind speed $(0.6 \mathrm{~m} / \mathrm{s})$ compared to the morning hours. In the afternoon, the wind speed was decreasing.

\subsection{Wind characteristics at the urban canyon}

For the comparative analysis of the anemological characteristics of the studied area, the data from the portable weather station which was recording data at a height of $1.8 \mathrm{~m}$, from the fixed wind sensors at a height of $4.5 \mathrm{~m}$ and from the meteorological station which was recording the meteorological conditions for the Greater Serres Area (GSA) were used. The analysis of data is referred at 13:00 and $16: 00 \mathrm{~h}$ and on the days that measurements by the portable weather station were conducted.

The research aimed at investigating the differences on air flow between the densely populated urban area and the suburban of the city. Also, the wind speed differences according to different heights and the time of the day is analyzed.

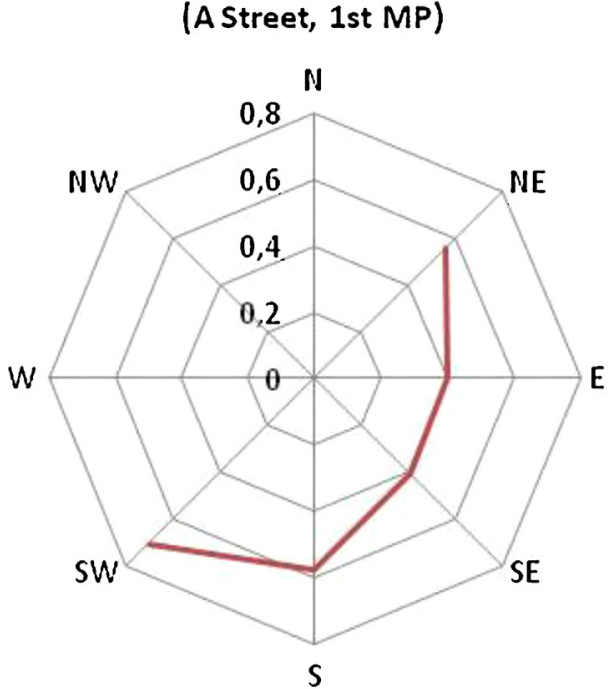

$S$

\section{(B Street, 4th MP)}

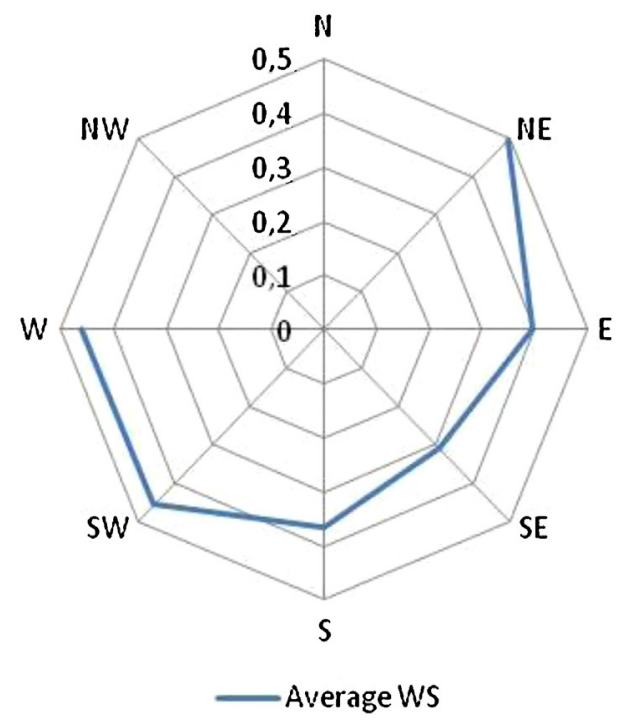

Fig. 5. Average wind speed for each wind direction in the two streets. 


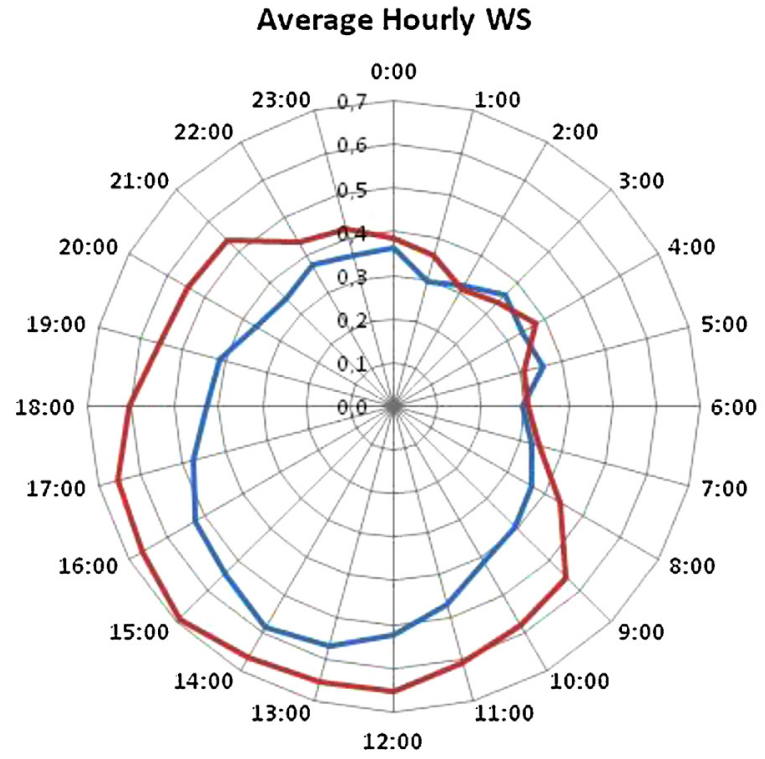

Average Hourly WS, B Street _ Average Hourly WS, A Street

Fig. 6. Hourly average wind speed for the two streets.

It is observed that the wind speed in GSA is higher than the wind speed (WS) inside the street canyon when the A Street is examined (Fig. 7). Also, as regards the wind speed in the study area, the speed at the pedestrian level $(1.8 \mathrm{~m})$ is higher than the speed at $4.5 \mathrm{~m}$. So, it is conducted that $\mathrm{WS}_{\mathrm{GSA}}>\mathrm{WS}_{1.8 \mathrm{~m}}>\mathrm{WS}_{4.5 \mathrm{~m}}$. The maximum wind speed was recorded during the afternoon (about 16:00 h) in all of three weather stations, regardless of the height of the weather station. Specifically, when the wind speed in the meteorological station GSA was $3.08 \mathrm{~m} / \mathrm{s}(14.08 .11,15: 52)$, the wind speed at the pedestrian's level was $0.73 \mathrm{~m} / \mathrm{s}$ and at $4.5 \mathrm{~m}$ was $0.61 \mathrm{~m} / \mathrm{s}$.

The wind speed in the GSA is higher than inside the B Street, too. The wind speed inside the canyon is not differentiated with the height. So, the speed is about the same in 1.8 and $4.5 \mathrm{~m}$ above the ground (Fig. 8).

So, the wind speed inside the streets in the urban center is lower than the wind speed in the suburban area. From the recorded data, it is observed that the wind speed in the urban canyons on pedestrian level and on $4.5 \mathrm{~m}$ is about the $1 / 3-1 / 4$ of the wind speed of the GSA.

\subsection{Air temperature distribution}

In order to investigate the mechanisms that determine the distribution of air temperature inside the street canyons in the city and the temperature differences between the urban center and the suburban area, air temperature measurements were performed inside the canyons. The air temperature distribution was analyzed in order to investigate the impact of the urban structure on microclimate.

In the study area, six fixed weather station for measuring the air temperature on $4.5 \mathrm{~m}$ height were placed, at intervals of $5 \mathrm{~min}$. The portable station recording the air temperature on $1.8 \mathrm{~m}$, in the six MP, in both sides of the road, specific days, at midday hours between 13:00 and 16:00 h. The ambient air temperature of the GSA was taken by the nearest suburban meteorological station of the Hellenic National Meteorological Service. This data referred in meteorological conditions, every $3 \mathrm{~h}$.

Fig. 9 presents the daily fluctuation of the average air temperature for all days that measurements took place. Each curve corresponds at a fixed station and shows the daily fluctuation of

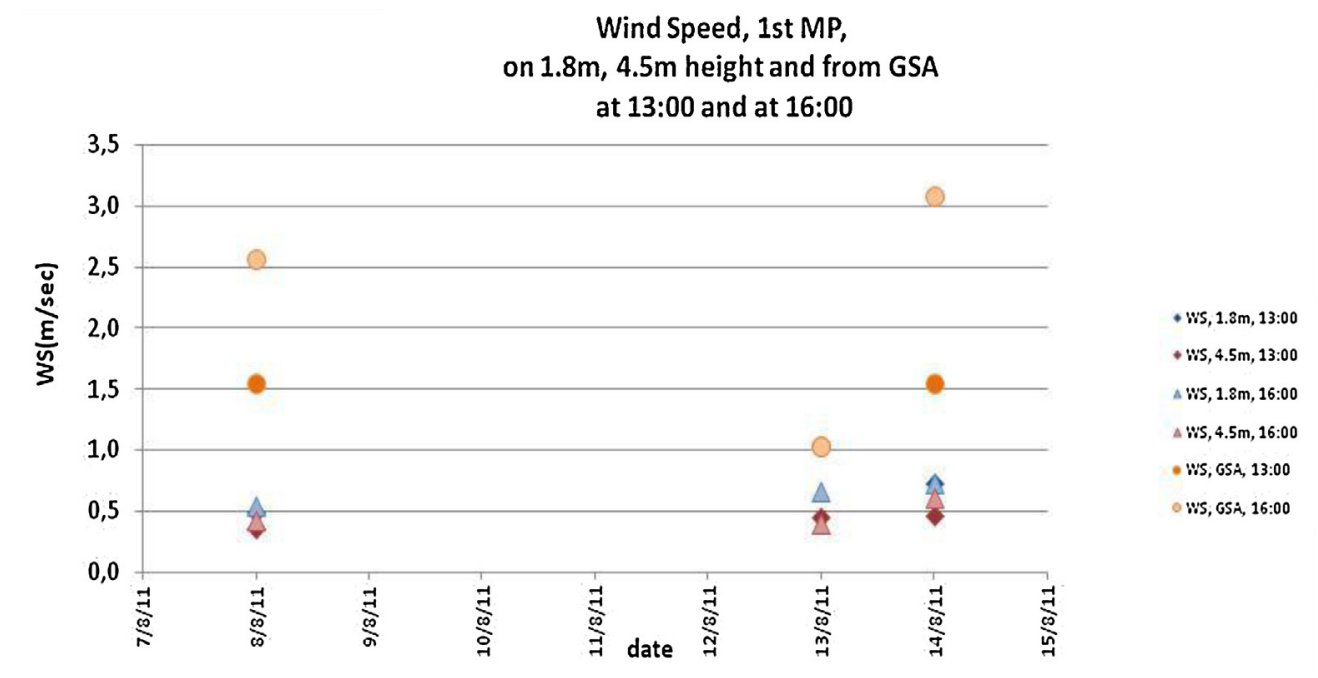

\begin{tabular}{|c|c|c|c|c|c|c|c|c|}
\hline \multicolumn{1}{|c|}{} & & $\begin{array}{c}\text { 1st Measurement Point } \\
\text { WD } \\
\text { Day }\end{array}$ & $\begin{array}{c}\text { WS } \\
(\mathrm{m} / \mathrm{sec}) \\
1.8 \mathrm{~m}\end{array}$ & $\begin{array}{c}\mathrm{WD} \\
\mathrm{W}\end{array}$ & $\begin{array}{c}\mathrm{WS} \\
(\mathrm{m} / \mathrm{sec})\end{array}$ & $\begin{array}{c}\mathrm{WS} \\
(\mathrm{m} / \mathrm{sec}) \\
\mathrm{GSA}\end{array}$ & $\Delta \mathrm{WS}_{(4.5-1.8)}$ & $\Delta \mathrm{WS}_{(\mathrm{GSA}-4.5)}$ \\
\hline $8 / 8 / 2011$ & $13: 00$ & 102.4 & 0.5 & 133.5 & 0.4 & 1.5 & -0.1 & 1.2 \\
\hline $13 / 8 / 2011$ & $13: 00$ & & & 154.4 & 0.4 & 1.0 & 0.4 & 0.6 \\
\hline $14 / 8 / 2011$ & $13: 00$ & 89.3 & 0.7 & 205.6 & 0.5 & 1.5 & -0.3 & 1.1 \\
\hline $8 / 8 / 2011$ & $16: 00$ & 210.8 & 0.5 & 200.2 & 0.4 & 2.6 & -0.1 & 2.1 \\
\hline $13 / 8 / 2011$ & $16: 00$ & 218.2 & 0.7 & 194.9 & 0.4 & 1.0 & -0.3 & 0.6 \\
\hline $14 / 8 / 2011$ & $16: 00$ & 199.7 & 0.7 & 230.6 & 0.6 & 3.1 & -0.1 & 2.5 \\
\hline
\end{tabular}

Fig. 7. Average hourly wind speed in the 1 st MP, in different measurement heights. 


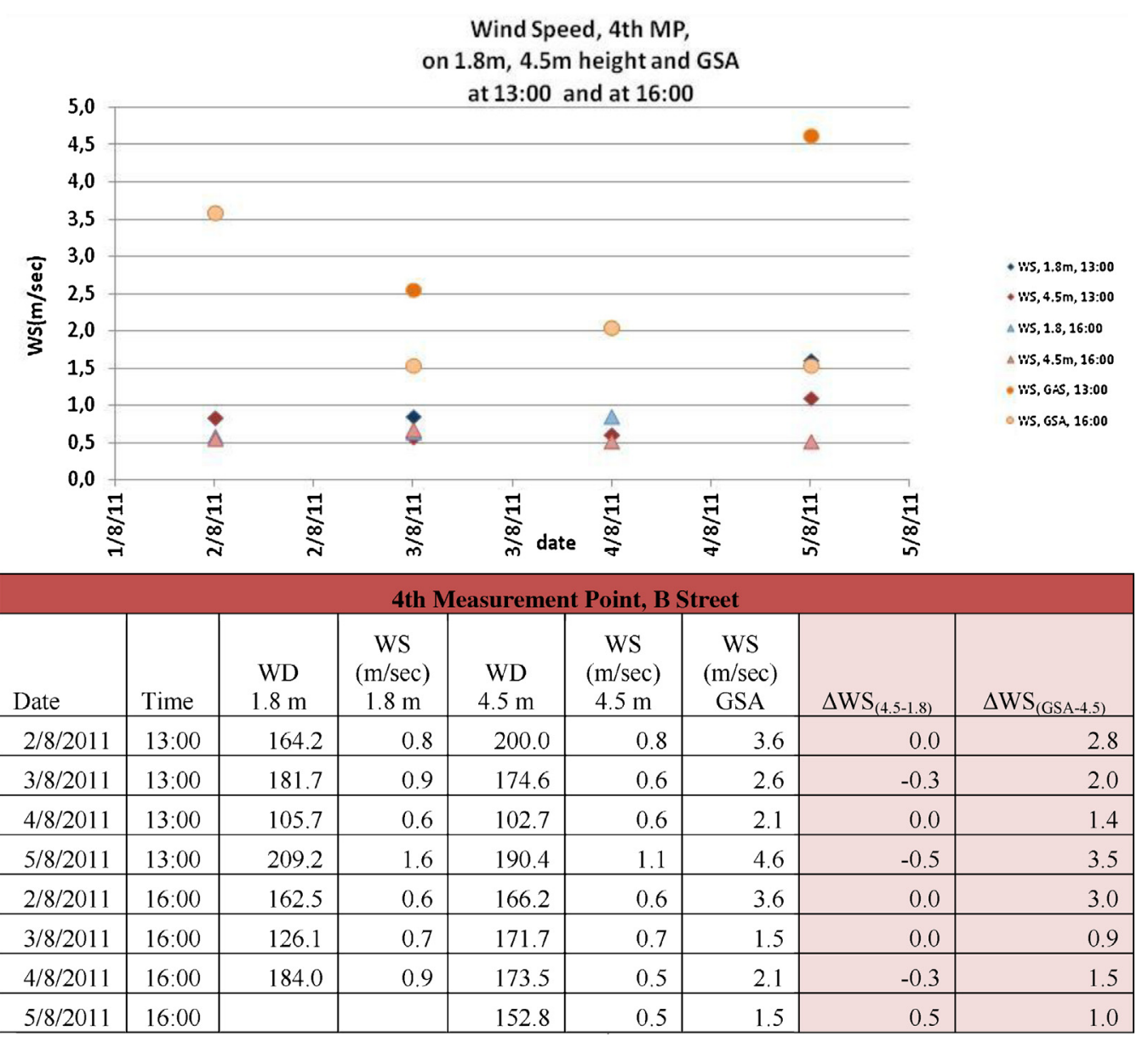

Fig. 8. Average hourly wind speed in the 4 th MP, in different measurement heights.

the air temperature, every $5 \mathrm{~min}$. The curve named GSA shows the temperature fluctuation for the greater area of the city, based on every $3 \mathrm{~h}$ data.

The maximum air temperature of GSA in the suburban area is observed at 12:00 a.m., while for the stations inside the urban center between 15:00 and 16:00 h, 3-4h later than in the suburban area. The air temperature in GSA is decreasing after mid-day (12:00) until 3:00 in the morning of next day when it starts increasing.
The temperature in the study urban area remains higher than GSA for more hours, because of the later appearance of the maximum temperature. At 15:00 p.m. the air temperature between the city's center and suburban is about the same, while at the next hours until 5:30 in the morning, the temperature is higher inside the streets.

The air temperature in the city is about $5.0-5.5^{\circ} \mathrm{C}$ higher than the suburban area during the afternoon and night (between

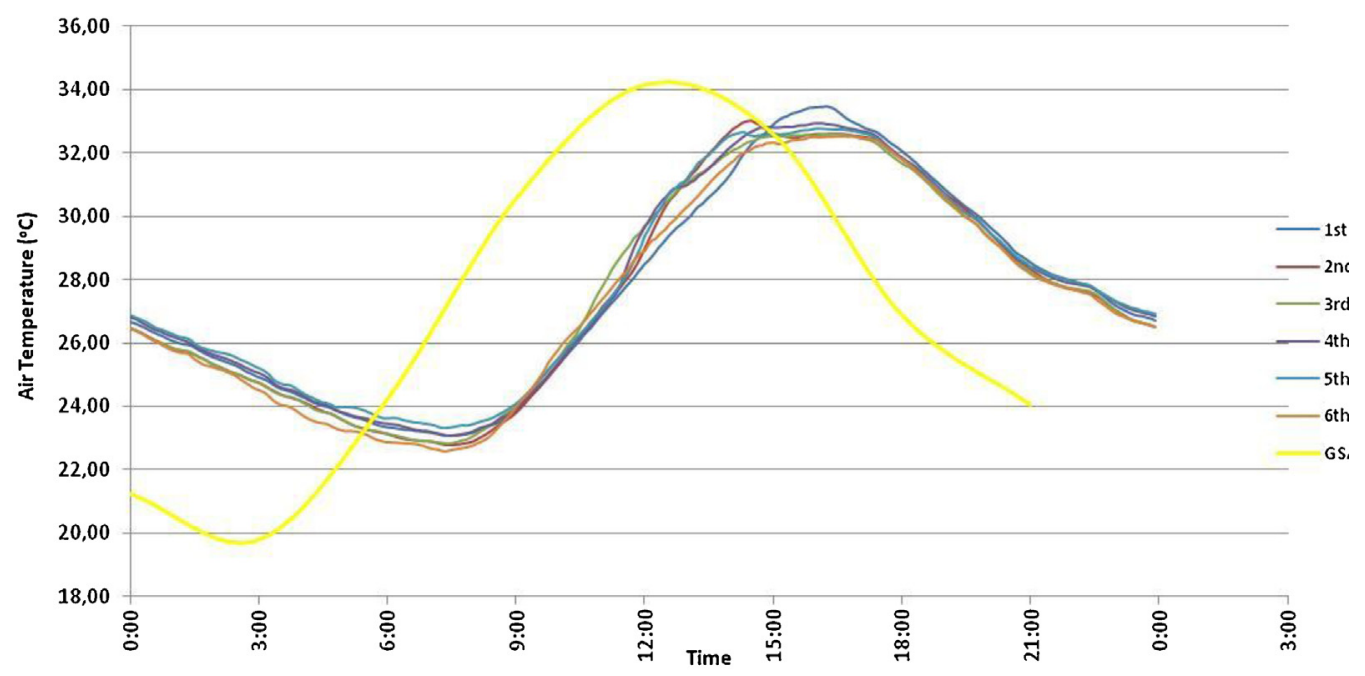

Fig. 9. Daily fluctuation of air temperature for the six MP inside the urban streets and GSA in the suburban. 


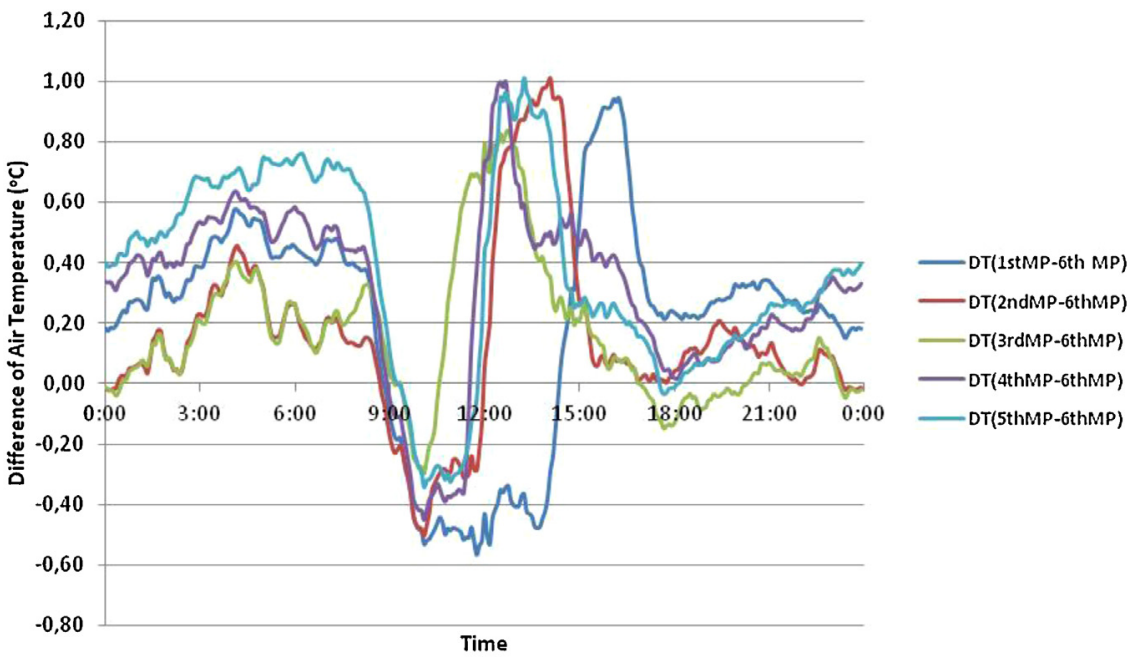

Fig. 10. Fluctuation of air temperature difference between each MP and 6th MP.

3:00 p.m. and 6:00 a.m.), while at the morning and early afternoon (6:00 p.m. to $3: 00$ p.m.) it is lower by up to about $7.0^{\circ} \mathrm{C}$.

Thus, the air temperature in the study area is maintained higher for longer time during the day. The high temperatures and the low wind speeds conditions inside the urban canyons of the study area result at unsatisfactory cooling and lack of ventilation potential of the streets. Also, the surfaces and the coating materials of the urban area absorb heat and remain thermally charged until late at afternoon, emitting larger amounts of heat to the environment for longer time periods. This contributes to further increase of air temperature, affects the urban microclimate of the area, encourages the development of urban heat island effect, and results at unsatisfactory thermal comfort conditions in outdoors spaces.

Comparison of air temperatures between measurement points inside the urban canyon and one measurement point which is located in an open area in a crossway of five roads with a green islet in the middle (6th MP). In Fig. 10, the difference of the 6th MP from each other MP, in daily basis can be obtained.

From the analysis of the data, the conclusion that is extracted is that the temperature inside the streets is higher than in the open area (6th MP). Exception is some time intervals, mainly during the morning hours were observed. These intervals were at 8:50-14:25 for the 1st MP, at 8:45-11:55 and 23:20-0:20 for the 2nd MP and at 9:25-10:30, 17:00-20:15 and 23:15-00:30 for the 3rd MP.
The temperature inside the streets is up to $0.8^{\circ} \mathrm{C}$ higher during the morning and up to $1.0^{\circ} \mathrm{C}$ higher during midday while during the afternoon and evening (17:00-0:00) the difference is less than $0.40 \mathrm{~K}$. This is an interesting observation, noted that the measurement points are near to the 6th MP at the same neighborhood. Especially the 4th MP and the 5th MP are along the same road but inside the urban canyon while the 6th MP is in a crossway.

\subsection{Estimation of the cooling degree hours in the study urban area}

In the analysis below (Table 5) the cooling degree hours (DH) are estimated. The temperature base for the degree hours estimation was considered to be $26^{\circ} \mathrm{C}$ for the summer period. The reference temperature of $26^{\circ} \mathrm{C}$ has been chosen according to the prevailing climatic condition in Greece and thermal comfort conditions [19].

For the period 27/7-24/8, for each of the six measurement points, the number of hourly temperatures which are higher than $26^{\circ} \mathrm{C}$ was estimated. Also, the percentages of degree hours which are higher of $26^{\circ} \mathrm{C}$ are presented. It is observed that these percentages are above $60 \%$ of the whole number of hourly temperatures, for all stations.

Considering that the reference temperature of $26^{\circ} \mathrm{C}$ for the existing relative humidity ensures thermal comfort conditions in

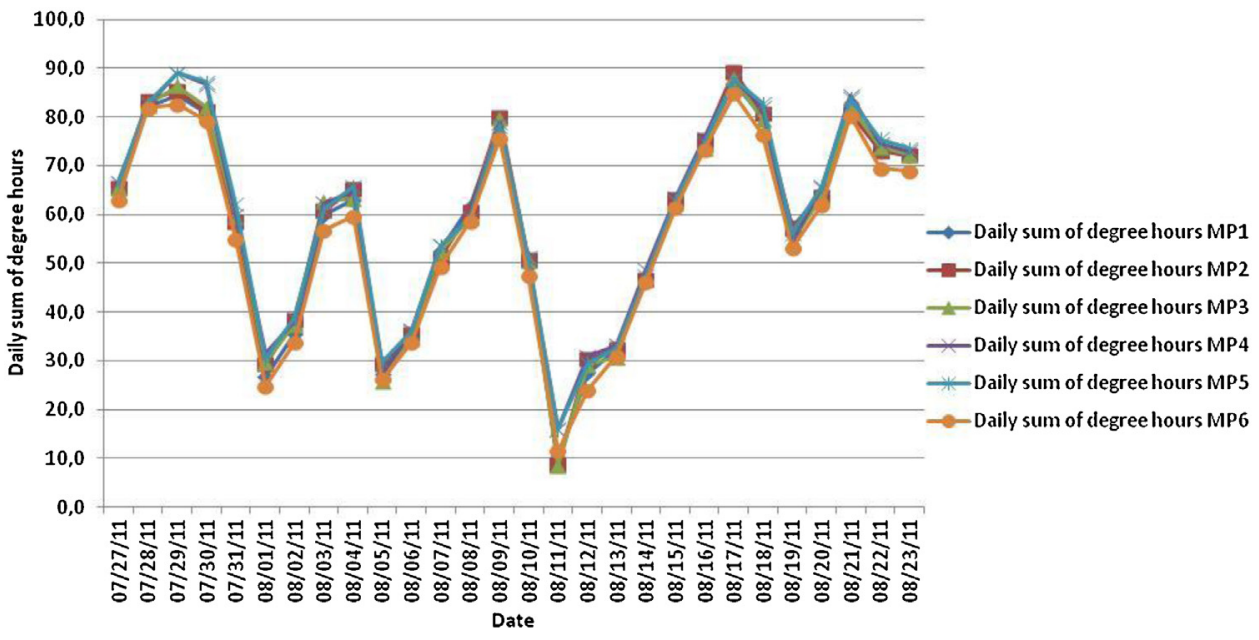

Fig. 11. Daily sum of degree hours for each Measuring Point (MP) based on $26^{\circ} \mathrm{C}$. 
Table 5

Cooling degree hours for each of the six measurement points.

\begin{tabular}{|c|c|c|c|c|c|c|}
\hline Measurement point (MP) & MP1 & MP2 & MP3 & MP4 & MP5 & MP6 \\
\hline No of hourly temperature $>26^{\circ} \mathrm{C}$, during $27 / 7-24 / 8$ & 413 & 409 & 412 & 421 & 428 & 404 \\
\hline Percentage of degree days $>26^{\circ} \mathrm{C}$, during $27 / 7-24 / 8$ & $61.46 \%$ & $60.86 \%$ & $61.31 \%$ & $62.65 \%$ & $63.69 \%$ & $60.12 \%$ \\
\hline
\end{tabular}

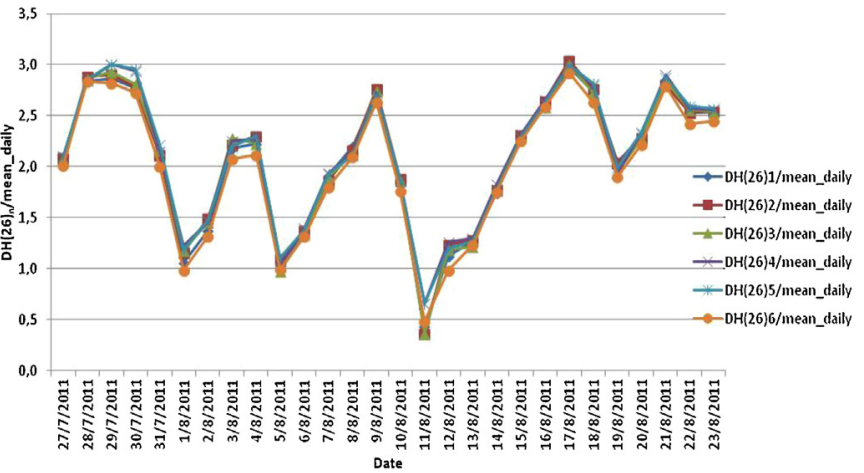

Fig. 12. Rations of $\Sigma \mathrm{DH}(26)_{i} / \mathrm{DH}($ mean daily temperature) for each MP.

external open spaces, it is concluded that the air temperature in the study area configure dissatisfactory microclimatic conditions inside the city. The increased cooling degree days are also associated with discomfort conditions inside the buildings and an increased demand for cooling energy for the surrounding buildings.

For the period of measurements, the daily sum of degree hours for each measurement point is presented in Fig. 11. The daily sum of the degree hours is between 10 and 90 .

Also, the ratio of the sum of degree hours to daily mean value of $\mathrm{DH}$ for each day, based on the mean daily air temperature for each day and each measurement point $i, \Sigma \mathrm{DH}(26)_{i} / \mathrm{DH}$ (mean daily temperature), is presented in Fig. 12. According to a previews study [19], when this ratio is greater that the unit then the corresponding station is considered as an urban station. The six monitoring stations are located in an urban area where air temperatures are higher than in the station that is located in the suburban area of Serres. Also, the study area is regarded as an area where the heat island effect appears. So, although the degree hours are not used for the determination of the thermal island effect [19], there is a coincidence in this study area between the determination of an urban station based on degree hours and the appearance of urban heat island.

\section{Conclusions}

The city of Serres, where the experimental study took place, is the warmest city of Northern Greece, according to the meteorological data of the Hellenic National Meteorological Service, for a period of 30 years.

According to the data analysis, the wind speeds inside the urban canyon in the study area are lower than in the suburban, GSA. Specifically, the wind speed in the pedestrians' level $(1.8 \mathrm{~m})$ is the $1 / 3-1 / 4$ of the suburban area. The wind direction differentiates according the geometry and orientation of the streets.

Because of the serious reduction of the wind speed in the urban canyons, there is an important limitation to apply natural and night ventilation in the dense urban environment. So, the city's blocks are not satisfactory ventilated. Natural ventilation is a wellknown technique that may contribute to restrict problems such as high ambient air temperatures due to urban heat island effect and degraded air quality. Also, it can contribute to the improvement of thermal comfort conditions in open urban spaces and to the decrease of energy consumption or need for air conditioning during summer period.

The air temperatures in the study area are about $5.0-5.5^{\circ} \mathrm{C}$ higher than in the suburban area, during the afternoon and night time. This is due to the urban configuration that obstructs the air flow and city's ventilation. Also, the constructive materials with high thermal conductivity and heat capacity (such as asphalt and covered materials) tend to conduct heat into their depths and to store more heat in their volume. This enhances the storage of heat during the day and its slow release at night, maintaining the temperature of ambient air on high levels. This increases the intensity of the phenomenon of urban heat island. Instead, during the morning the air temperatures in the city are $7.0^{\circ} \mathrm{C}$ lower.

Also, the estimated cooling degree hours demonstrated that the percentages of values that are greater than $26^{\circ} \mathrm{C}$ are above to $60 \%$. Likewise, the six measurement points are urban stations and they are locates in an area where the urban heat island effect is appeared. The increased cooling degree days are also associated with discomfort conditions inside the buildings and an increased demand for cooling energy for the surrounding buildings.

The above results indicate the important role and how the urban geometry configures and alters the microclimatic conditions in an area. The morphological characteristic of city's planning (width of roads, height of buildings etc.), the existence of open and green areas and the constructive and covered materials influence the air flow inside the urban canyons and the thermal balance in the local microclimate.

\section{Acknowledgements}

The study was financed by the Municipality of Serres for the "Investigation of bioclimatic rehabilitation of open spaces in an urban area of the Serres city".

Special thanks to the staff of the Municipality of Serres for the technical support for the execution of the project and for the installation of the fixed weather stations and for all providing services.

\section{References}

[1] M. Santamouris, Heat island research in Europe: the state of the art, Advances Building Energy Research 1 (2007) 123-150.

[2] N. Gaitani, A. Spanou, M. Saliari, A. Synnefa, K. Vassilakopoulou, K. Papadopoulou, Improving the microclimate in urban areas: a case study in the centre of Athens, Building Services Engineering Research and Technology 32 (1) (2011) 53-71.

[3] S.S.Y. Lau, F. Yang, J. Tai, X.L. Wu, J. Wang, The study of summer-time heat island, built form and fabric in a densely built urban environment in compact Chinese cities: Hong Kong, Guangzhou, International Journal of Sustainable Development $14(1 / 2)(2011) 30-48$.

[4] D. Kolokotsa, A. Psomas, E. Karapidakis, Urban heat island in southern Europe: the case study of Hania, Crete, Solar Energy 83 (2009) 1871-1883.

[5] T. Mohsin, W.A. Gough, Characterization and estimation of urban heat island at Toronto: impact of the choice of rural sites, Theoretical Applied Climatology (2011), http://dx.doi.org/10.1007/s00704-011-0516-7.

[6] T.R. Oke, D.G. Johnson, D.G. Steyn, I.D. Watson, Simulation of surface urban heat island under 'ideal' conditions at night. Part 2: diagnosis and causation, Boundary-Layer Meteorology 56 (4) (1991) 339-358.

[7] M. Santamouris (Ed.), Energy and Climate in the Urban Built Environment, James and James Science, London, 2001.

[8] C. Georgakis, M. Santamouris, Experimental investigation of air flow and temperature distribution in deep urban canyons for natural ventilation purposes, Energy and Buildings 38 (4) (2006) 367-376.

[9] E. Stathopoulou, G. Mihalakakou, M. Santamouris, H.S. Bagiorgas, Impact of temperature on tropospheric ozone concentration levels in urban environments, Earth System Science 117 (3) (2008) 227-236. 
[10] E. Oikonomou, M. Davies, A. Mavrogianni, P. Biddulph, P. Wilkinson, M. Kolokotroni, Modelling the relative importance of the urban heat island and the thermal quality of dwellings for overheating in London, Building and Environment 57 (2012) 223-238.

[11] C. Cartalis, A. Synodinou, M. Proedrou, A. Tsangrassoulis, M. Santamouris, Modifications in energy demand in urban areas as a result of climate changes: an assessment for the southeast Mediterranean region, Journal of Energy Conversion and Management 42 (14) (2001) 1647-1656.

[12] M. Santamouris, K. Paraponiaris, G. Mihalakakou, Estimating the ecological footprint of the heat island effect over Athens, Greece, Climate Change 80 (2007) 265-276.

[13] N. Gaitani, G. Michalakakou, M. Santamouris, On the use of bioclimatic architecture principles in order to improve thermal comfort conditions in outdoor spaces, Building and Environment 42 (1) (2007) 317-324.
[14] M. Santamouris (Ed.), Energy and Climate in the Urban Built Environment: The Role of Green Spaces, James \& James Science, London, 2001, pp. 145-159.

[15] A. Dimoudi, Urban design, in: M. Santamouris, D. Assimakopoulos (Eds.), Passive Cooling of Buildings, Earthscan, London, 1996, pp. 95-128.

[16] A. Dimoudi, M. Nikolopoulou, Vegetation in the urban environment: microclimatic analysis and benefits, Energy and Buildings 35 (1) (2003) 69-76.

[17] L. Gartland, Heat Islands, Understanding and Mitigating Heat in Urban Areas, Earthscan, London, 2008

[18] A. Kantzioura, P. Kosmopoulos, S. Zoras, Urban surface temperature and microclimate measurements in Thessaloniki, Energy and Buildings 44 (2012) 63-72.

[19] I. Livada, M. Santamouris, K. Niachou, N. Papanikolaou, G. Mihalakakou, Determination of places in the great Athens area where the heat island effect is observed, Theoretical and Applied Climatology 71 (2002) 219-230. 